\title{
PHOTONIC EFFICIENCY FOR METHANOL PHOTOOXIDATION AND HYDROXYL RADICAL GENERATION ON SILICA-SUPPORTED TiO PHOTOCATALYSTS
}

\author{
Javier Marugán ${ }^{\text {a }}$, Dirk Hufschmidt ${ }^{\mathrm{b}}$, María-José López-Muñoz ${ }^{\mathrm{a}}$, Volker Selzer ${ }^{\mathrm{b}}$, Detlef \\ Bahnemann $^{\mathrm{b}}$. \\ ${ }^{a}$ ESCET. Universidad Rey Juan Carlos. C/ Tulipán s/n, 28933 Móstoles, Madrid, Spain. \\ ${ }^{\mathrm{b}}$ Universitaet Hannover. Institut fuer Technische Chemie (TCI). Callinstrasse 3, D-30167 \\ Hannover, Germany. \\ Phone: +34 6647466 ; Fax: +34 4887068 ; E-Mail: javier.marugan@urjc.es
}

Published on:

Applied Catalysis B: Environmental, Volume 62: 201-207 (2006).

doi:10.1016/j.apcatb.2005.07.013 


\begin{abstract}
Hydroxyl radical species are considered to be responsible for many oxidation pathways of chemical compounds initiated by advanced oxidation technologies and particularly in heterogeneous photocatalytic processes. However, not many attempts have been made to quantify the generation rate of these species for newly developed photocatalysts, especially for the large number of supported photocatalysts synthesized during the last years. This work focuses on the evaluation of the photonic efficiency for the hydroxyl radical generation on several silica supported $\mathrm{TiO}_{2}$ photocatalysts recently developed. The study has been carried out by using methanol as hydroxyl radical scavenger. The influence of the mesoporous structure of the support and of its titania loading on the photonic efficiency of the materials has been analyzed. The importance of diffusional restrictions within the porous structure of the support has also been investigated by using a larger hydroxyl radical scavenger molecule, namely n-butanol.
\end{abstract}

Keywords: Photonic efficiency, methanol, n-butanol, hydroxyl radicals, supported $\mathrm{TiO}_{2}$ 


\section{Introduction}

Advanced oxidation technologies have been widely proposed during recent years for the detoxification of a large number of chemical pollutants present in industrial wastewater $[1,2]$. Many of these processes are based on the use of hydroxyl radicals as strong oxidants resulting in the non-selective degradation of almost all toxic and non biodegradable pollutants. Among them, the photocatalytic oxidation has been demonstrated to be applicable for a wide number of potential applications [3-10]. These processes are based on the use of a semiconductor material that generates electron/hole pairs when being illuminated with radiation above the energy of its band-gap. The most widely used semiconductor materials are based on $\mathrm{TiO}_{2}$. Many attempts to improve their catalytic properties have been made in order to facilitate its commercial application in the liquid phase.

In order to compare the activity of different photocatalytic materials, reaction rates must be referred to either the incident or the absorbed photon flux. These parameters, called photonic efficiency or quantum yield, respectively, have traditionally been used by different authors but not always with the same meaning. Definition and standardized methods for their calculation can be found in the literature $[11,12]$, together with others parameters such as relative photonic efficiencies for different materials determined employing the same experimental conditions.

One of the usual ways to modify a photocatalyst is to deposit the semiconductor onto an inert support in order to improve the recovery of the solids after the reactions [13-14]. The results found in the literature show that the presence of the support usually reduces the activity of the catalysts. Usually, this can be explained by higher restrictions of the mass transport of the chemicals to the photocatalyst surface [15] and by a lower photon flux absorbed by the semiconductor due to an increased light scattering by the support. However, despite the large number of supported photocatalysts prepared in the last years, not many attempts have been made to quantify the activity of these materials in terms of standardized parameters such as photonic efficiencies.

Hydroxyl radical species have been proposed to be the responsible for many oxidation pathways of chemical compounds initiated through heterogeneous photocatalytic processes [7]. The $\cdot \mathrm{OH}$ radical generation takes place through the oxidation of bound $\mathrm{OH}$ ions or water molecules adsorbed on the material, being the primary step that leads to the total mineralization of the pollutants. For that reason, the measurement of the rate of the hydroxyl radical generation is one of the most important parameters to be studied during the evaluation of newly developed photocatalysts. This measurement leads to very useful results for the 
comparison of the photoactivity of different materials, independent of the specific degradation mechanism of the selected pollutants.

In order to quantify the rate of $\cdot \mathrm{OH}$ generation, it has been proposed to use a well-known hydroxyl radical scavenger, i.e., methanol. Previous studies [16-19] have demonstrated the possibility of using high concentrations of methanol to quantify the complete hydroxyl radical production from the photogenerated holes at the semiconductor surface.

We have studied the photonic efficiencies of the hydroxyl radical generation for some silicasupported $\mathrm{TiO}_{2}$ photocatalysts developed recently [20]. In particular, the photocatalytic oxidation of methanol yielding formaldehyde has been investigated. These results have been compared with the photocatalytic activity obtained when Degussa P25 $\mathrm{TiO}_{2}$ was used as photocatalyst. As the silica support plays an important role for the activity of these materials, the diffusion of chemicals inside the porous structure of the support has also been investigated. Among the different variables involved in the synthesis of the catalysts studied here, the influence of the titania loading and of the type of silica support has been analyzed.

\section{Experimental procedure}

\subsection{Catalysts synthesis and characterization}

The silica-supported $\mathrm{TiO}_{2}$ photocatalysts have been prepared employing a previously reported method [20]. The incorporation of $\mathrm{TiO}_{2}$ clusters into the support was accomplished via a solgel route, starting with the required amount of titanium tetraisopropoxide and resulting in the condensation of $\mathrm{TiO}_{2}$ inside the porous structure of the support. Two different types of mesoporous silica materials have been used as supports: an amorphous commercial $\mathrm{SiO}_{2}$ (Grace Sylopol 2104, $\mathrm{GrSiO}_{2}$ ) with a wide pore size distribution of mesopores and a mesostructured silica material called SBA-15 with a very well defined pore size.

The characterization of the samples shows the presence of nanocrystalline clusters of anatase with different sizes in the range of 6-12 $\mathrm{nm}$ depending on both the type of support and the weight percent of titania loading. The activity of these materials is also affected by the titania loading and the chosen silica support. Details about the synthesis, characterization and photoactivity of these materials have been reported previously [20,21].

\subsection{Photocatalytic activity tests}


The photoreactor consisted of a Pyrex reactor with an effective volume of 1 litre. UV irradiation was performed by a $150 \mathrm{~W}$ medium pressure mercury lamp (Heraeus TQ-150) placed inside a quartz jacket and equipped with a cooling tube. Cooling of the system was achieved by the circulation of an aqueous $0.01 \mathrm{M} \mathrm{CuSO}_{4}$ solution resulting in the absorption of radiation wavelengths below $325 \mathrm{~nm}$, thus avoiding photolytic processes. The UV-A incident photon flow, determined by ferrioxalate actinometry, was $1.10 \cdot 10^{-5}$ Einstein $1^{-1} \mathrm{~s}^{-1}$. The lamp was switched on 30 minutes before the beginning of the reaction to stabilize the power of its emission spectrum line at $365 \mathrm{~nm}$. The temperature of the cooling agent was also stabilized to perform the reactions at $25 \pm 0.1^{\circ} \mathrm{C}$.

Reactions were carried out suspending the amount of catalyst required to obtain a titania concentration of $0.5 \mathrm{~g} \mathrm{TiO}_{2} \mathrm{l}^{-1}$. It has been experimentally verified that this catalyst concentration leads to a negligible UV-A radiation flux through the outer wall of the reactor with all tested photocatalysts. The suspensions were sonicated and saturated with molecular oxygen by bubbling for 30 minutes. Afterwards, methanol was added in the desired concentration and thereafter suspensions were stirred in the dark for 30 minutes to reach the adsorption equilibrium prior to the irradiation.

Samples were withdrawn at regular intervals from the upper part of the reactor with the catalyst being removed from the liquid phase by filtration through $0.22 \mu \mathrm{m}$ nylon syringe filters. The extent of the photodegradation was determined by measuring the formaldehyde production employing the Nash method [22]. This method is based on the reaction of formaldehyde with acetylacetone and ammonium to form a coloured product with a maximum of absorbance at $412 \mathrm{~nm}$, measured after an incubation time of 60 minutes. For the n-butanol photodegradation experiments, butanal concentrations were measured following the same colorimetric method as that used for formaldehyde analysis, but measuring the absorbance at $385 \mathrm{~nm}$ after an incubation time of 24 hours at $25^{\circ} \mathrm{C}$.

\section{Results and discussion}

\subsection{Influence of methanol concentration and silica support.}

According to previous studies of the photocatalytic methanol oxidation, formaldehyde is the only stable product formed initially under reaction conditions employing an excess of methanol [16-18]. Consequently, the amount of methanol oxidized is identical to that of the detected formaldehyde concentration. Thus, the photonic efficiency can either be calculated 
from the reactant disappearance rate or from the product formation rate. The initial photonic efficiencies were calculated as $\xi=r_{\mathrm{HCHO}}^{0}\left(\mathrm{~mol} \cdot \mathrm{l}^{-1} \cdot \mathrm{s}^{-1}\right) / I\left(\right.$ Einstein $\left.\cdot l^{-1} \cdot \mathrm{s}^{-1}\right)$, where $r_{\text {HCHO }}^{0}$ is the initial slope of the formaldehyde formation profile and $I$ is the incident photon flow.

Figure 1 shows formaldehyde formation profiles obtained during the photocatalytic oxidation of $30 \mathrm{mM}$ methanol in aqueous suspensions of Degussa P25 $\mathrm{TiO}_{2}$ and of two different silica supported photocatalysts with $20 \%$ of titania loading. It is obvious that the activity of both $\mathrm{TiO}_{2} /$ silica materials is lower than that shown by the commercial $\mathrm{TiO}_{2}$ powder. The initial reaction rate values are $0.0279 \mathrm{mmol} \mathrm{min}^{-1}, 0.0173 \mathrm{mmol} \mathrm{min}^{-1}$ and $0.0147 \mathrm{mmol} \mathrm{min}^{-1}$ for Degussa P25, 20\% $\mathrm{TiO}_{2} / \mathrm{SBA}-15$ and $20 \% \mathrm{TiO}_{2} / \mathrm{GrSiO}_{2}$, respectively. The lower activity of the supported catalysts can in principle be explained by three different factors: i) a lower intrinsic activity of the $\mathrm{TiO}_{2}$ semiconductor crystals; ii) a kinetic control of the internal mass transport due to a low diffusion rate into the porous structure of the support; and iii) a lower absorption of the incident photon flux thus reducing the photonic efficiency.

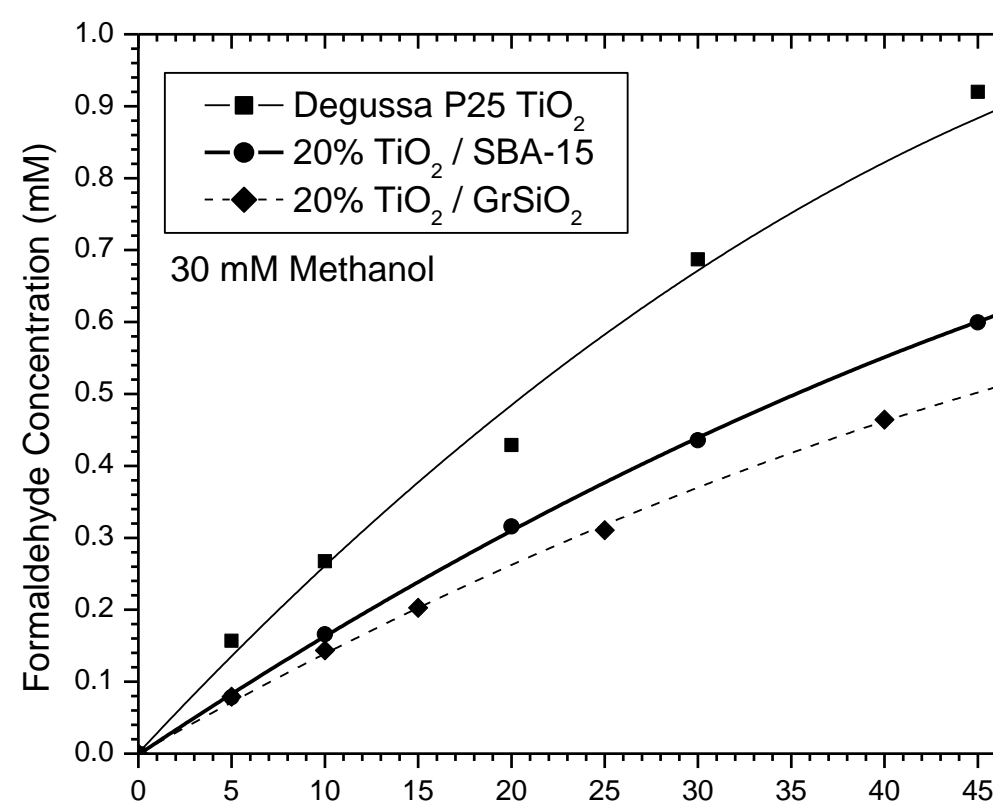

Figure 1. Formaldehyde production from $30 \mathrm{mM}$ methanol solutions $\left(\mathrm{C}_{\text {Catal }}=0.5 \mathrm{~g} \mathrm{TiO}{ }_{2} \cdot \mathrm{l}^{-1}\right.$;

$$
\left.I^{0}=1.1 \cdot 10^{-5} \text { Einsteinl } \cdot 1^{-1} \cdot \mathrm{s}^{-1} \text {; natural } \mathrm{pH} ; \mathrm{T}=25^{\circ} \mathrm{C}\right) \text {. }
$$

In order to elucidate the main factors affecting the activity of these materials additional experiments at higher methanol concentrations were carried out. In Figure 2 the results for formaldehyde generation from $2 \mathrm{M}$ methanol solutions are depicted. The initial reaction rate 
values calculated from these profiles for Degussa P25, 20\% $\mathrm{TiO}_{2} / \mathrm{SBA}-15$ and $20 \% \mathrm{TiO}_{2} / \mathrm{GrSiO}_{2}$ are $0.0464 \mathrm{mmol} \cdot \mathrm{min}^{-1}, 0.0457 \mathrm{mmol} \cdot \mathrm{min}^{-1}$ and $0.0382 \mathrm{mmol} \cdot \mathrm{min}^{-1}$, respectively. It is important to notice that, whereas the increase in activity for Degussa P25 is found to be less than $100 \%$, both supported photocatalysts increase their initial reaction reactions almost by a factor of three. In fact, at this methanol concentration, the initial photoxidation rate shown by the catalyst $20 \% \mathrm{TiO}_{2} / \mathrm{SBA}-15$ is almost identical to that measured with Degussa P25 powder $\mathrm{TiO}_{2}$.

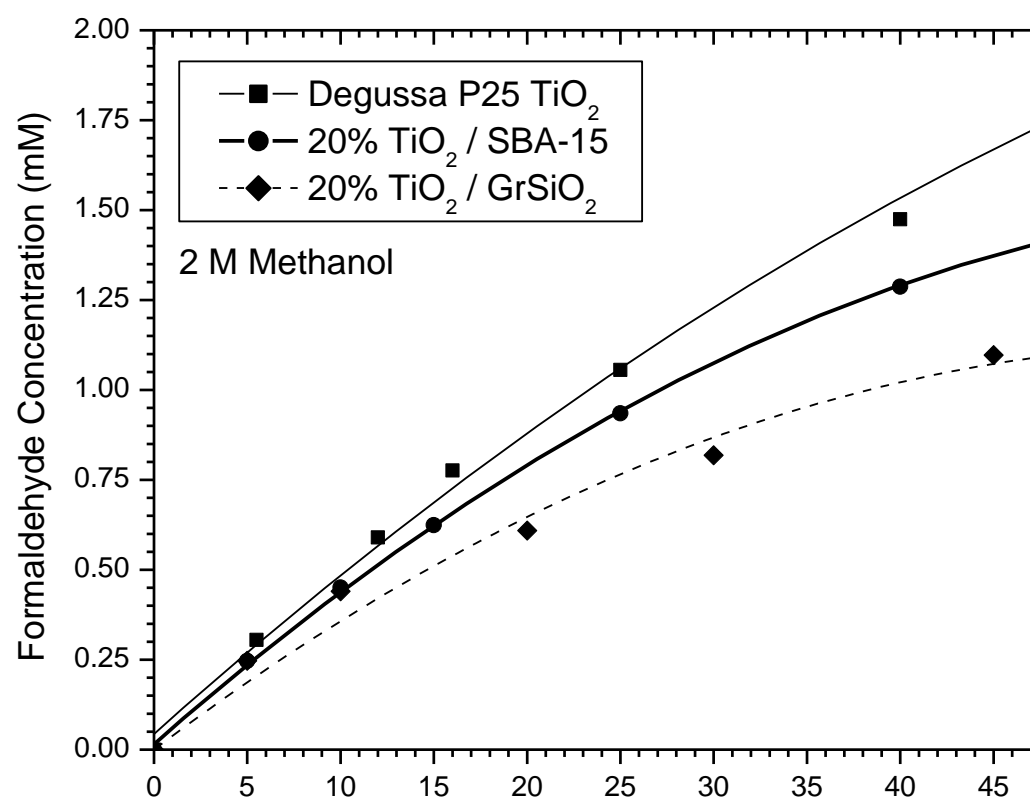

Figure 2. Formaldehyde production from $2 \mathrm{M}$ methanol solutions $\left(\mathrm{C}_{\text {Catal }}=0.5 \mathrm{~g} \mathrm{TiO}_{2} \cdot 1^{-1} ; I^{0}=\right.$ $1.1 \cdot 10^{-5}$ Einsteinl $\cdot 1^{-1} \cdot \mathrm{s}^{-1}$; natural $\left.\mathrm{pH} ; \mathrm{T}=25^{\circ} \mathrm{C}\right)$.

Taking into account that identical optical conditions are assured by using the same photocatalyst concentrations at both methanol concentrations, the comparison of the results displayed in Figures 1 and 2 offers important information about the intrinsic activity of every catalyst and the possible existence of diffusional problems. First of all, the almost identical activity observed for the supported catalyst and for Degussa P25 as the methanol concentration is increased, clearly indicates the existence of a kinetic control of the global reaction rate by the internal mass transport of the reactant. Assuming that only the external transport is required to reach the semiconductor surface for $\mathrm{TiO}_{2}$ powder and that internal diffusion problems can be neglected at these high methanol concentrations, the intrinsic activity of the catalyst $20 \% \mathrm{TiO}_{2} / \mathrm{SBA}-15$ must be virtually the same as that of Degussa P25. 
On the other hand, the higher activity of the SBA-15 supported photocatalyst in comparison with the amorphous silica based material must be due to one or maybe several of the following reasons: i) a higher intrinsic activity of the $\mathrm{TiO}_{2}$ crystals of the $20 \% \mathrm{TiO}_{2} / \mathrm{SBA}-15$ catalyst; ii) a lower diffusion rate into the porous structure of the $20 \% \mathrm{TiO}_{2} / \mathrm{GrSiO}_{2}$; or iii) a higher radiation absorptivity of the $20 \% \mathrm{TiO}_{2} / \mathrm{SBA}-15$ material.

Summarizing some of the main characterization data of these materials reported elsewhere $[20,21]$, the $\mathrm{TiO}_{2} / \mathrm{GrSiO}_{2}$ catalysts consist of spheres of $10-70 \mu \mathrm{m}$ in diameter with a wide pore size distribution centered at $19 \mathrm{~nm}$ that produced a wide range of $\mathrm{TiO}_{2}$ crystal sizes. Concerning the $\mathrm{TiO}_{2} / \mathrm{SBA}-15$ materials, the particle size is about $1 \mu \mathrm{m}$ and, what is more important, they present a very narrow pore size distribution that restricts the $\mathrm{TiO}_{2}$ particle growth producing very homogeneous semiconductor crystals with a diameter of 6-7 nm. Taking into account these features, the possibility of a lower diffusion rate on the porous structure of the amorphous silica support must be discarded, because, in fact, the wider pore size of these materials must certainly produce the contrary effect. Additionally, it is wellknown that, for the same mass concentration, particles of smaller size exhibit a higher volumetric scattering coefficient. Therefore, the absorption to scattering ratio could probably be higher for $\mathrm{TiO}_{2} / \mathrm{GrSiO}_{2}$ rather than for $\mathrm{TiO}_{2} / \mathrm{SBA}-15$ catalysts. Based upon these considerations, we conclude that the superior values measured for the methanol oxidation on $20 \% \mathrm{TiO}_{2} / \mathrm{SBA}-15$ must be explained in terms of an intrinsically higher activity of the $\mathrm{TiO}_{2}$ crystals, as both the diffusional and optical phenomena would favor an increased activity of the amorphous silica based material.

\subsection{Influence of the $\mathrm{TiO}_{2}$ loading}

Materials with different wt $\%$ of $\mathrm{TiO}_{2}$ loadings on both silica supports have been tested in order to investigate the influence of the semiconductor content on the photocatalytic methanol oxidation. Table 1 summarizes the initial reaction rates and the values of the photonic efficiencies obtained with every catalyst during the photocatalytic oxidation of $30 \mathrm{mM}$ methanol in aqueous suspensions of the catalysts. It is important to notice that reactions were carried out with the required amount of catalyst to obtain a loading of $0.5 \mathrm{~g} \mathrm{TiO}_{2} \mathrm{l}^{-1}$, as detailed in the experimental section. Activity data referring to Degussa P25 $\mathrm{TiO}_{2}$ are also given as relative photonic efficiencies $\left(\xi_{\mathrm{r}}\right)$. This value is defined as the ratio between the photonic efficiency of each material and that determined for the P25 sample. The use of this 
parameter enables an easier comparison between the activity results. It is obvious that all the supported catalysts show a relative activity smaller than 0.7 as compared with Degussa P25. Concerning the influence of an increasing $\mathrm{TiO}_{2}$ loading on the activity, Table 1 shows that only a slight increase is obtained when SBA-15 is used as support. The use of amorphous silica leads to a better improvement in the photonic efficiency as the wt $\%$ of $\mathrm{TiO}_{2}$ increases. This different behaviour means that whereas $\mathrm{TiO}_{2} / \mathrm{SBA}-15$ materials present a higher activity for low $\mathrm{TiO}_{2}$ loadings, similar results are obtained with both silica supports for the highest semiconductor content.

Table 1. Initial reaction rates and photonic efficiencies of $30 \mathrm{mM}$ methanol photoxidation.

\begin{tabular}{|c|c|c|c|}
\hline Photocatalyst & $\begin{array}{c}\mathbf{r}_{\mathrm{HCHO}}^{0} \\
\left(\mathrm{mmol} \mathrm{l}^{-1} \mathrm{~min}^{-1}\right)\end{array}$ & $\begin{array}{c}\xi \\
\left(\text { mol }_{\text {HСно }} \text { Einstein }^{-1}\right)\end{array}$ & $\xi_{\mathbf{r}}$ \\
\hline Degussa P25 & 0.028 & 0.043 & 1.00 \\
\hline $20 \% \mathrm{TiO}_{2} / \mathrm{SBA}-15$ & 0.017 & 0.026 & 0.61 \\
\hline $40 \% \mathrm{TiO}_{2} / \mathrm{SBA}-15$ & 0.019 & 0.029 & 0.68 \\
\hline $60 \% \mathrm{TiO}_{2} / \mathrm{SBA}-15$ & 0.019 & 0.029 & 0.68 \\
\hline $20 \% \mathrm{TiO}_{2} / \mathrm{GrSiO}_{2}$ & 0.015 & 0.023 & 0.54 \\
\hline $40 \% \mathrm{TiO}_{2} / \mathrm{GrSiO}_{2}$ & 0.018 & 0.027 & 0.64 \\
\hline $60 \% \mathrm{TiO}_{2} / \mathrm{GrSiO}_{2}$ & 0.019 & 0.029 & 0.68 \\
\hline
\end{tabular}

Regarding the use of higher methanol concentrations, Table 2 summarizes the activity results obtained with each catalyst during the photocatalytic oxidation of $2 \mathrm{M}$ methanol in aqueous suspensions of the photocatalysts. As observed for the catalysts containing $20 \mathrm{wt} \%$ of $\mathrm{TiO}_{2}$, the activity presented the supported materials are close to that obtained with Degussa P25, especially with $\mathrm{TiO}_{2} / \mathrm{SBA}-15$. Additionally, the influence on the activity by the wt $\%$ of $\mathrm{TiO}_{2}$ depends on the support. Whereas the activity of the SBA-15 supported photocatalysts seems to be independent upon the semiconductor content, materials supported on amorphous silica increase their activity at higher $\mathrm{TiO}_{2}$ loadings reaching similar values to those obtained with the SBA-15 support. 
Table 2. Initial reaction rates and photonic efficiencies of $2 \mathrm{M}$ methanol photoxidation.

\begin{tabular}{|c|c|c|c|}
\hline Photocatalyst & $\begin{array}{c}\mathbf{r}_{\mathrm{HCHO}}^{0} \\
\left(\mathrm{mmol} \mathrm{l}^{-1} \min ^{-1}\right)\end{array}$ & $\begin{array}{c}\xi \\
\left(\text { mol }_{\text {Hсно Einstein }}{ }^{-1}\right)\end{array}$ & $\xi_{\mathrm{r}}$ \\
\hline Degussa P25 & 0.046 & 0.070 & 1.00 \\
\hline $20 \% \mathrm{TiO}_{2} / \mathrm{SBA}-15$ & 0.046 & 0.070 & 1.00 \\
\hline $40 \% \mathrm{TiO}_{2} / \mathrm{SBA}-15$ & 0.043 & 0.065 & 0.93 \\
\hline $60 \% \mathrm{TiO}_{2} / \mathrm{SBA}-15$ & 0.043 & 0.065 & 0.93 \\
\hline $20 \% \mathrm{TiO}_{2} / \mathrm{GrSiO}_{2}$ & 0.038 & 0.058 & 0.83 \\
\hline $40 \% \mathrm{TiO}_{2} / \mathrm{GrSiO}_{2}$ & 0.039 & 0.059 & 0.85 \\
\hline $60 \% \mathrm{TiO}_{2} / \mathrm{GrSiO}_{2}$ & 0.044 & 0.067 & 0.96 \\
\hline
\end{tabular}

To explain these results, the optical behaviour of the different materials must be considered. All reactions have been performed at constant $\mathrm{TiO}_{2}$ concentrations, thus, for the catalysts with higher $\mathrm{TiO}_{2}$ loading, less mass of support is present, or, in other words, less silica particles are supporting the same amount of $\mathrm{TiO}_{2}$. Although similar intrinsic activities of the $\mathrm{TiO}_{2}$ crystals independently of the $\mathrm{TiO}_{2}$ loading can be assumed, a decrease in the diffusion rate inside the porous structure is to be expected. On the contrary, from the optical point of view, an increase in the absorption to scattering ratio can be expected. Taking into account both phenomena, the results obtained by using amorphous silica as support can be explained by the improvement in the optical behaviour while the decrease in diffusion rate will be negligible because of their open porous structure. In contrast, a higher $\mathrm{TiO}_{2}$ content of the SBA-15 mesoporous channels could produce diffusional restrictions of the mass transport thus limiting the improvement of the activity produced by the optical features.

Interesting results has also been recently reported about methanol photoxidation over titanium dioxide clusters dispersed in MCM-41 [23,24]. These works has demonstrated an important role of the reactant - substrate interaction in photocatalytic processes in vapour phase. However, their conclusions cannot be directly extrapolated to the photocatalytic oxidation in aqueous suspensions.

\subsection{Photonic efficiency for hydroxyl radical generation}

According to Wang et al. [18], methanol photoxidation to formaldehyde takes place through the following mechanism: 


$$
\begin{aligned}
& \mathrm{TiO}_{2}+\mathrm{hv} \rightarrow \mathrm{e}_{\mathrm{CB}}^{-}+\mathrm{h}^{+}{ }_{\mathrm{VB}} \\
& \mathrm{h}^{+}{ }_{\mathrm{VB}}+\mathrm{OH}^{-} \rightarrow \cdot \mathrm{OH} \\
& \mathrm{e}_{\mathrm{CB}}^{-}+\mathrm{O}_{2} \rightarrow \cdot \mathrm{O}_{2}^{-} \\
& \cdot \mathrm{OH}+\mathrm{CH}_{3} \mathrm{OH} \rightarrow \mathrm{H}_{2} \mathrm{O}+\mathrm{CH}_{2} \mathrm{OH} \\
& \cdot \mathrm{CH}_{2} \mathrm{OH}+\mathrm{O}_{2} \rightarrow \cdot \mathrm{O}_{2} \mathrm{CH}_{2} \mathrm{OH} \rightarrow \mathrm{HCHO}+\cdot \mathrm{O}_{2}^{-}+\mathrm{H}^{+} \\
& \cdot \mathrm{O}_{2}^{-}+\mathrm{O}_{2}^{-}+2 \mathrm{H}^{+} \rightarrow \mathrm{O}_{2}+\mathrm{H}_{2} \mathrm{O}_{2} \\
& \mathrm{e}_{\mathrm{CB}}^{-}+\mathrm{H}_{2} \mathrm{O}_{2} \rightarrow \cdot \mathrm{OH}+\mathrm{OH}^{-}
\end{aligned}
$$

It has been suggested that this oxidation process does not take place through a direct hole transfer mechanism but rather through the intermediacy of hydroxyl radicals being eventually the only oxidant species [16].

Table 3 summarizes the photonic efficiencies for hydroxyl radical formation calculated for all catalysts from the photoxidation of $2 \mathrm{M}$ methanol solutions. These values have been calculated assuming the relation $\phi_{\text {Methanol }}=2 \cdot \phi \cdot \mathrm{OH}$, in agreement with the oxidation mechanism reported in the literature [18]. Since an initial methanol concentration of $2 \mathrm{M}$ has been shown to be able of trapping all photogenerated $\cdot \mathrm{OH}$ radicals [19], these values can be taken as the maximum photonic efficiency obtainable in a $\cdot \mathrm{OH}$ radical mediated photocatalytic oxidation.

Table 3. Photonic efficiencies of hydroxyl radical generation.

\begin{tabular}{lc}
\hline Photocatalyst & $\xi\left(\right.$ mol.oH Einstein $\left.^{-\mathbf{1}}\right)$ \\
\hline Degussa P25 & 0.035 \\
$20 \% \mathrm{TiO}_{2} / \mathrm{SBA}-15$ & 0.035 \\
$40 \% \mathrm{TiO}_{2} / \mathrm{SBA}-15$ & 0.033 \\
$60 \% \mathrm{TiO}_{2} / \mathrm{SBA}-15$ & 0.033 \\
$20 \% \mathrm{TiO}_{2} / \mathrm{GrSiO}_{2}$ & 0.029 \\
$40 \% \mathrm{TiO}_{2} / \mathrm{GrSiO}_{2}$ & 0.030 \\
$60 \% \mathrm{TiO}_{2} / \mathrm{GrSiO}_{2}$ & 0.033 \\
\hline
\end{tabular}

3.4. Use of n-butanol as hydroxyl radical scavenger. 
Additional experiments have been carried out in order to investigate the influence of the internal diffusion within the supported photocatalysts. Therefore, n-butanol has been chosen as hydroxyl radical scavenger to compare the results obtained with methanol with those measured for a bigger molecule. Butanal generation has been chosen to follow the reaction as it has been shown to be the first intermediary product obtained in the photocatalytic oxidation of n-butanol [25]. Figure 3 shows the butanal generation profiles obtained during the photoxidation of $30 \mathrm{mM}$ n-butanol solutions with Degussa P25, 20\% $\mathrm{TiO}_{2} / \mathrm{SBA}-15$ and $20 \% \mathrm{TiO}_{2} / \mathrm{GrSiO}_{2}$, respectively. The initial reaction rate and the values for the photonic efficiency are given in Table 4.

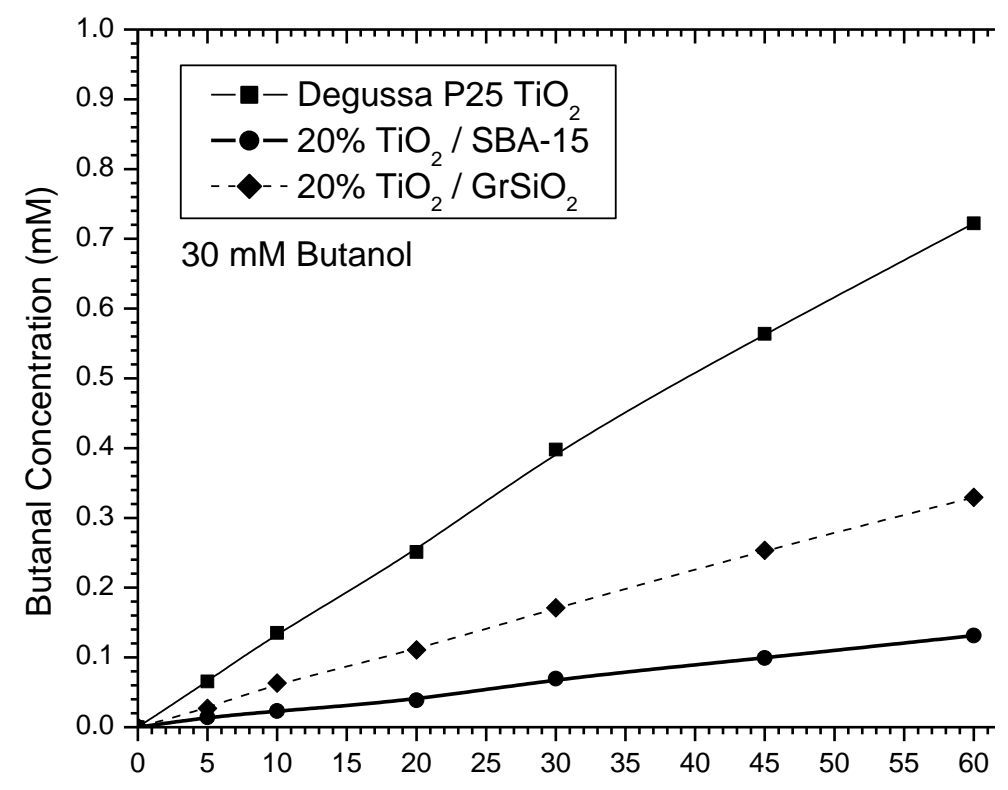

Figure 3. Photoxidation of $30 \mathrm{mM}$ n-butanol solutions $\left(\mathrm{C}_{\text {Catal }}=0.5 \mathrm{~g} \mathrm{TiO}_{2} \cdot 1^{-1} ; I^{0}=1.1 \cdot 10^{-5}\right.$ Einsteinl $\cdot 1^{-1} \cdot \mathrm{s}^{-1}$; natural $\left.\mathrm{pH} ; \mathrm{T}=25^{\circ} \mathrm{C}\right)$.

Table 4. Initial reaction rates and photonic efficiencies of $30 \mathrm{mM}$ butanol photoxidation.

\begin{tabular}{lccc}
\hline Photocatalyst & $\begin{array}{c}\mathbf{r}_{\text {Butanal }}^{\mathbf{0}} \\
\left(\mathbf{m m o l ~ l}^{\mathbf{- 1}} \mathbf{~ m i n}^{\mathbf{- 1}}\right)\end{array}$ & $\begin{array}{c}\xi \\
\left(\mathbf{m o l}_{\text {Butanal }} \text { Einstein }^{\mathbf{- 1}}\right)\end{array}$ & $\boldsymbol{\xi}_{\mathbf{r}}$ \\
\hline Degussa P25 & 0.025 & 0.038 & 1.00 \\
$20 \% \mathrm{TiO}_{2} / \mathrm{SBA} 15$ & 0.004 & 0.006 & 0.16 \\
$20 \% \mathrm{TiO}_{2} / \mathrm{GrSiO}_{2}$ & 0.011 & 0.017 & 0.44 \\
\hline
\end{tabular}


First of all, it should be noticed that the photonic efficiency for the n-butanol oxidation with Degussa P25 is smaller than that for the methanol oxidation of identical substrate concentration. Taking into account that Degussa $\mathrm{P} 25 \mathrm{TiO}_{2}$ has no porous structure, mass transport problems can be neglected to explain this difference. Thus, this result indicates a slower reaction rate of $\mathrm{n}$-butanol with the surface adsorbed $\cdot \mathrm{OH}$ radical formed upon bandgap illumination of this photocatalyst. Additionally, it could be also indicated the formation of additional oxidation products different from butanal. However, this lower activity is almost negligible in comparison with the dramatic decrease in activity observed for the $20 \% \mathrm{TiO}_{2} / \mathrm{SBA}-15$ photocatalyst. Finally, the material $20 \% \mathrm{TiO}_{2} / \mathrm{GrSiO}_{2}$ shows a moderate decrease in activity, reducing its relative photonic efficiency in relation to $\mathrm{P} 25 \mathrm{TiO}_{2}$ from 0.53 for methanol photoxidation to 0.45 for n-butanol photoxidation.

These differences in activity can be explained in terms of a diffusional control. The open porous structure of the $\mathrm{TiO}_{2} / \mathrm{GrSiO}_{2}$ materials produces only a slight decrease in the diffusion rate of n-butanol as compared with methanol. However, the much closer porous structure of the $\mathrm{TiO}_{2} / \mathrm{SBA}-15$ material drastically reduces the diffusion rate when n-butanol is used as the reactant instead of methanol. Similar results have been recently reported for the photodegradation of different cyanide containing species [26].

Taking into account the possible diffusion of free $\cdot \mathrm{OH}$ radicals to the solution would imply similar activities for both catalysts. Consequently, these results also confirm the commonly accepted mechanism for the photocatalytic oxidation via hydroxyl radicals involving the diffusion of the reactant to the $\mathrm{TiO}_{2}$ surface to react with the adsorbed $\cdot \mathrm{OH}$ radicals.

Further experiments with higher concentrations of n-butanol confirm this hypothesis. Figure 4 shows the butanal generation profiles obtained for the photoxidation of $350 \mathrm{mM}$-butanol solutions. In this case, higher concentrations cannot be used because this value is very close to the maximum solubility of $n$-butanol in water. The initial reaction rate and the photonic efficiency values calculated for these reactions are summarized in Table 5. It is apparent that the increase in n-butanol concentration enhanced the photocatalytic activity for both supported catalysts as compared with powdered $\mathrm{TiO}_{2}(\mathrm{P} 25)$, due to the diffusional control in former systems. Moreover, as the kinetic control by mass transport phenomena is more important for the SBA-15 supported materials, the increase in the activity for these catalysts in relative terms is higher than for the amorphous silica based materials. 


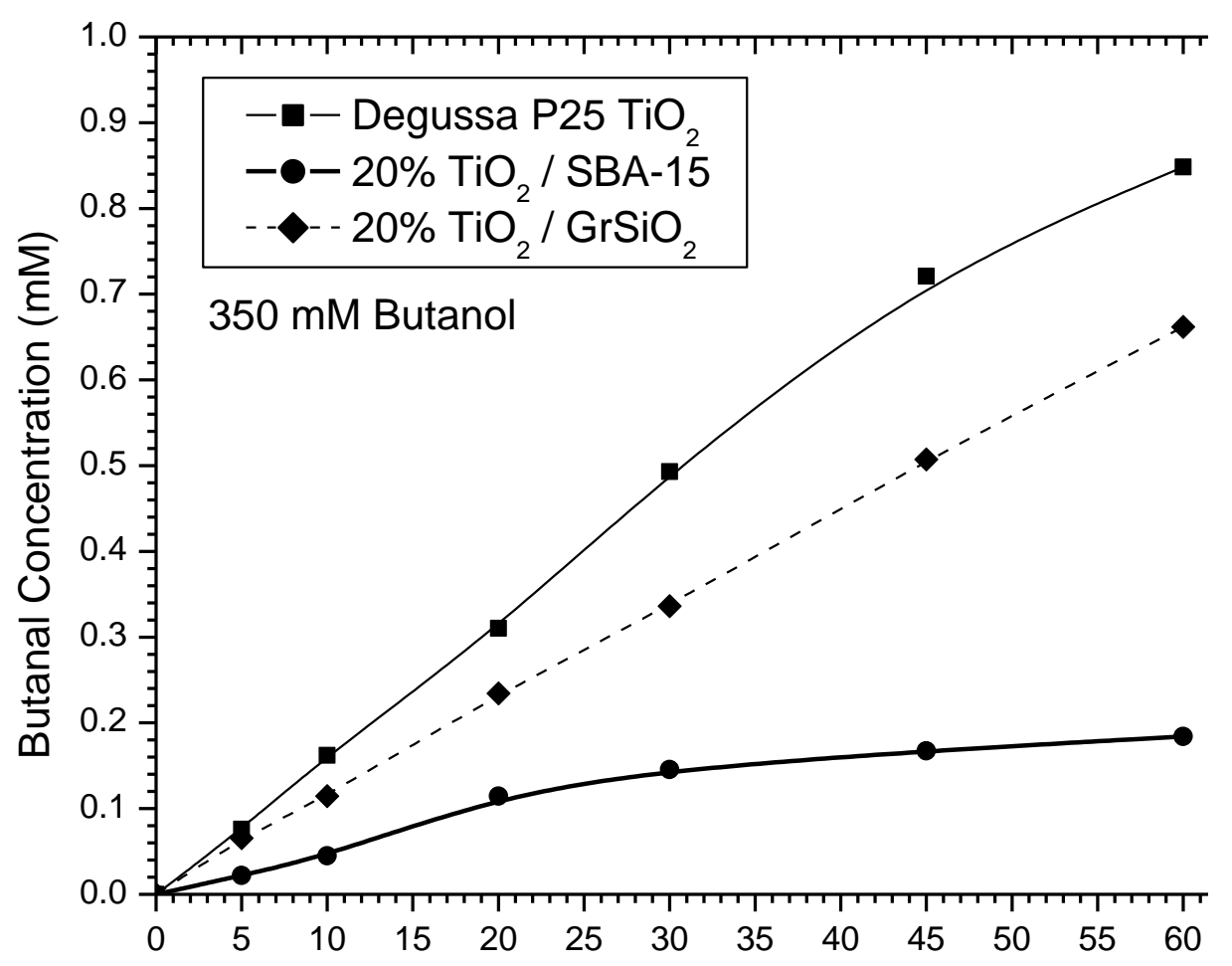

Figure 4. Photoxidation of $350 \mathrm{mM}$-butanol solutions $\left(\mathrm{C}_{\mathrm{Catal}}=0.5 \mathrm{~g} \mathrm{TiO} \cdot \mathrm{T}^{-1} ; I^{0}=1.1 \cdot 10^{-5}\right.$ Einsteinl $\cdot 1^{-1} \cdot \mathrm{s}^{-1} ;$ natural $\left.\mathrm{pH} ; \mathrm{T}=25^{\circ} \mathrm{C}\right)$.

Table 5. Initial reaction rates and photonic efficiencies of $350 \mathrm{mM}$ butanol photoxidation.

\begin{tabular}{|c|c|c|c|}
\hline Photocatalyst & $\begin{array}{c}\mathbf{r}_{\text {Butanal }}^{0} \\
\left(\mathrm{mmol} \mathrm{l}^{-1} \min ^{-1}\right)\end{array}$ & $\begin{array}{c}\xi \\
\left(\text { mol }_{\text {Butanal }} \text { Einstein }^{-1}\right)\end{array}$ & $\xi_{\mathbf{r}}$ \\
\hline Degussa P25 & 0.033 & 0.050 & 1.00 \\
\hline $20 \% \mathrm{TiO}_{2} / \mathrm{SBA}-15$ & 0.012 & 0.018 & 0.36 \\
\hline $20 \% \mathrm{TiO}_{2} / \mathrm{GrSiO}_{2}$ & 0.022 & 0.033 & 0.67 \\
\hline
\end{tabular}

\section{Conclusions}

Any evaluation of newly developed photocatalysts must be carefully done in order to clearly distinguish the rate-limiting step within the observed global kinetics. This is very important especially for supported catalysts for which differences in their optical properties and restrictions to mass transport phenomena must be taken into account. 
The $\mathrm{TiO}_{2} / \mathrm{SBA}-15$ photocatalyst shows a very high intrinsic activity of the $\mathrm{TiO}_{2}$ clusters fixed to the matrix for hydroxyl radical generation and therefore most likely for the photocatalytic oxidation of almost any chemical pollutant. However, the same characteristic structure of the support that produces these highly active semiconductor crystals is responsible of the existence of important diffusional restrictions to the mass transport. For that reason, the relative photonic efficiency of these catalysts strongly depends on the nature and on the concentration of the specific pollutant being oxidized.

\section{Acknowledgements}

The authors thank "Consejería de Educación, Comunidad de Madrid" for the financial support of this research through the project "Contrato-Programa Grupos Estratégicos de Investigación" and "Ministerio de Ciencia y Tecnología” through the project PPQ2000-1287.

\section{References}

[1] Calgon Carbon Oxidation Technologies “The AOT Handbook”, Ontario, 1996.

[2] Office of Research and Development - USEPA, Handbook on Advanced Photochemical Oxidation Processes, Washington, 1998.

[3] D. Blake, Bibliography of work on the Photocatalytic removal of hazardous compounds from water and air, (May 1994; $1^{\text {st }}$ update: October 1994; $2^{\text {nd }}$ update: October 1996; $3^{\text {rd }}$ update: January 1999; $4^{\text {th }}$ update: October 2001), NREL, Golden, CO.

[4] D.F. Ollis, E. Pellizzetti, N., Serpone, Environ. Sci. Tech. 25 (1991) 1522.

[5] M. Fox, M. Dulay, Chem. Rev. 93 (1993) 341.

[6] D.F. Ollis, H. Al-ekabi (Eds.), Photocatalytic Purification and Treatment of Water and Air, Elsevier, Amsterdam, 1993.

[7] M.R. Hoffmann, S.T. Martin, W. Choi, D.W. Bahnemann, D.W., Chem. Rev. 95 (1995) 69.

[8] D.F. Ollis, Cat. Tech. 2 (1998) 149.

[9] J.M. Herrmann, Catal. Today 53 (1999) 115.

[10] O.M. Alfano, D. Bahnemann, A.E. Cassano, R. Dillert, R. Goslich, Catal. Today 58 (2000) 199.

[11] A. Salinaro, A.V. Emeline, J. Zhao, H. Hidaka, V.K. Ryabchuk, N. Serpone, Pure \& Appl. Chem. 71 (1999) 321.

[12] N. Serpone, A. Salinaro, Pure \& Appl. Chem. 71 (1999) 303. 
[13] R.L. Pozzo, M.A. Baltanás, A.E. Cassano, Catal. Today 39 (1997) 219.

[14] J.A. Byrne, B.R. Eggins, N.M.D. Brown, B. McKinney, M. Rouse, Appl. Catal. B: Environ. 17 (1998) 25.

[15] D. Chen, F. Li, A.K. Ray, Catal. Today 66 (2001) 475.

[16] L. Sun, J.R. Bolton., J. Phys. Chem. 100 (1996) 4127.

[17] C. Wang, D.W. Bahnemann, J.K. Dohrmann, Wat. Sci. Tech. 44 (2001) 279.

[18] C. Wang, J. Rabani, D.W. Bahnemann, J.K. Dohrmann, J. Photochem. Photobiol. A: Chem. 148 (2002) 169.

[19] R. Gao, J. Stark, D.W. Bahnemann, J. Rabani, J. Photochem. Photobiol. A: Chem. 148 (2002) 387.

[20] R. van Grieken, J. Aguado, M.J. López-Muñoz, J. Marugán, J. Photochem. Photobiol. A: Chem. 148 (2002) 315.

[21] J. Aguado, R. van Grieken, M.J. López-Muñoz, J. Marugán, Catal. Today 75 (2002) 95.

[22] T. Nash, Biochem. J. 55 (1953) 416.

[23] K. Bhattacharya, A.K. Tripathi, G.D. Dey, N.M. Gupta, Nanoscience Technol. 5 (2005) 790.

[24] K. Bhattacharya, S. Varma, D. Kumar, A.K. Tripathi, N.M. Gupta, Nanoscience Technol. 5 (2005) 797.

[25] J. Kirchnerova, M.L. Herrera Cohen, C. Guy, D. Kvlana, Appl. Catal A: Gen. 282 (2005) 321.

[26] M.J. Lopez-Muñoz, R. van Grieken, J. Aguado, J. Marugán, Catal. Today 101 (2005) 307. 